\title{
Functional polymorphism in aldehyde dehydrogenase- 2 gene associated with risk of tuberculosis
}

\author{
Seung Kyu Park' Choon-Sik Park ${ }^{2}$, Hyo-Suk Lee ${ }^{3}$, Kyong Soo Park ${ }^{4}$, Byung Lae Park ${ }^{5}$, Hyun Sub Cheong ${ }^{5}$ \\ and Hyoung Doo Shin ${ }^{5,6^{*}}$
}

\begin{abstract}
Background: The well-known genetic polymorphisms in ADH1B(His47Arg) and ALDH2(Glu487Lys) have dramatic effects on the rate of metabolizing alcohol and acetaldehyde. We investigated possible involvement of these functional polymorphisms in other common complex-trait diseases.

Methods: The genetic effects of these two polymorphisms on hepatitis, asthma, type-2 diabetes mellitus (T2DM), and tuberculosis (TB) were examined in a Korean population.

Results: We demonstrated that the well-known functional polymorphism of a primary alcohol-metabolizing enzyme (ALDH2 Glu487Lys) has a strong genetic association with the risk of TB. The frequency of the minor allele (ALDH2*487Lys) was found to be much lower in TB patients (freq. $=0.099 / \mathrm{n}=477$ ) than among controls (freq. $=0.162 / \mathrm{n}=796$ ) $(\mathrm{P}=0.00001, \mathrm{OR}(95 \%$ confidential interval $)=0.57(0.45-0.74))$. Our data may indicate that TB was once an endemic disease, which exerted selection pressure for higher frequencies of $A L D H 2 * 487 L y s$ in Asian populations. In addition, the calculated attributable fraction (AF) indicates that $39.5 \%$ of TB patients can attribute their disease to the detrimental effects of ALDH2Glu487Glu.
\end{abstract}

Conclusion: Our results suggest that this polymorphism is one of the genetic components of TB, at least in the Korean population.

Keywords: Aldehyde dehydrogenase, Tuberculosis, Polymorphism

\section{Background}

The alcohol dehydrogenases (ADHs), especially ADH1B, convert alcohol to acetaldehyde. Subsequently, the aldehyde dehydrogenases (ALDHs), mainly ALDH2, oxidate the acetaldehyde into acetate. Encoding genes for these two representative alcohol-metabolizing enzymes display polymorphisms $(A D H 1 B$ His47Arg and $A L D H 2$ Glu487Lys) that show different alcohol/acetaldehyde oxidizing capability among individuals [1-4]. The ADH1B*47His allele represents a much higher activity of ADH1B with about 40 times higher Vmax than the homozygotes for

\footnotetext{
* Correspondence: hdshin@sogang.ac.kr

${ }^{5}$ Department of Genetic Epidemiology, SNP Genetics, Inc., 1 Shinsu-dong, Mapo-gu, Seoul 121-742, Republic of Korea

${ }^{6}$ Department of Life Science, Sogang University, 1 Shinsu-dong, Mapo-gu, Seoul 121-742, Republic of Korea

Full list of author information is available at the end of the article
}

the $A D H 1 B * 47 \operatorname{Arg}$ form, which enables increased alcohol elimination from the blood after alcohol consumption $[1,5]$. The $A L D H 2 * 487 L y s$ allele encodes a catalytically inactive subunit $[1,5]$, which causes alcohol-related adverse reactions [6]. These adverse reactions in subjects with $A L D H 2 * 487 L y s$, as a result of excessive acetaldehyde accumulation, tend to reduce alcohol consumption, consequently reducing the risk of alcoholism.

We previously demonstrated that $A D H 1 B^{*} 47 \mathrm{Arg}$ and ALDH2*487Lys were dramatically associated with the risk of alcoholism in a Korean population [7,8]. In addition, when combined, the two loci revealed major genetic effects on the risk of alcoholism [9]. To investigate possible involvement of these functional polymorphisms in other common complex-trait diseases, we examined their genetic effects on HBV (hepatitis B virus)

\section{Biomed Central}


hepatitis, asthma, type-2 diabetes mellitus (T2DM), and tuberculosis (TB) in a Korean population.

\section{Methods}

\section{Study subjects and genotyping of polymorphisms}

Information about the study subjects was provided in previous studies (number of samples may differ slightly) as follows: HBV (hepatitis B virus) hepatitis [10], asthma [11], T2DM [12], and tuberculosis (TB) [13]. Briefly, the following subjects were included: a total of 963 subjects for the hepatitis study (537 chronic carriers [mean age $=55.0$, range $=23-82]$ and 426 spontaneously recovered subjects from hepatitis B [mean age $=55.0$, range $=29-79]$ ), 1,796 subjects for the asthma study (1,259 asthma patients [mean age $=33.8$, range $=22-65$ ] and 537 controls [mean age $=37.1$, range $=32-56]), 1,359$ subjects for the T2DM study $(745$ T2DM patients [mean age $=57.1$, range $=43$ 72 ] and 614 controls [mean age $=65.5$, range $=45-76$ ]), 1,032 subjects for the alcoholism study (549 alcoholics [all males; mean age $=46.1$, range $=20-73]$ and 483 controls [all male; mean age $=33.2$, range $=20-77]$ ), and 1,273 subjects for the TB study (447 TB patients [all male; mean age $=46.7$, range $=20-86$ ] and 796 controls [all male; mean age $=54.9$, range $=40-69]$ ). Inclusion criteria were described in previous studies [11-13].

\section{Statistics}

$X^{2}$ tests were used to determine if the individual variants were in Hardy-Weinberg equilibrium (HWE). Logistic regression analyses, controlling for age and gender as covariates, were used to calculate odds ratios and the $P$-values for case-control analysis. All statistical analyses were performed using SAS 9.1 (SAS Institute, Inc., Cary, NC, USA). The attributable fraction (AF) was calculated by the formula $\mathrm{AF}=f(R \cdot-1) /(1+f(R \cdot-1))$, where $f$ is the frequency of the risk factor in the population, and $R$ is the measure of the odds ratio [14].

\section{Results}

The genotype distributions of $A D H 1 B$ His47Arg and ALDH2Glu487Lys were not found to deviate from HWE $(\mathrm{P}>0.05)$ except in alcoholic patients $(A D H 1 B$ His47Arg). (For comparison, the results of our previous study of two polymorphisms and their association with alcoholism [9] have been added to Table 1). Logistic regression analysis did not show any significant association with the clearance of hepatitis B virus or with the risks of asthma, T2DM, or TB (Table 1). However, a strong genetic association of ALDH2Glu487Lys with the risk of TB was observed. The frequency of the minor allele was much lower in TB patients (freq. $=0.099 / \mathrm{n}=477$ ) than in controls (freq. = $0.162 / \mathrm{n}=796)(\mathrm{P}=0.00001$, OR $(95 \%$ confidential inter$\mathrm{val})=0.57(0.45-0.74)$, Table 1$)$. The overall allele frequencies of $A L D H 2 * 487 L y s$ ranged from $0.161-0.181$, except in alcoholic patients (freq. $=0.017$ ) and $\mathrm{TB}$ patients (freq. $=$ 0.099), in the Korean population.

Further referent and alternative (co-dominant, dominant, and recessive model) analysis of ALDH2Glu487Lys revealed that its genetic mode for the risk of TB is apparently protective and dominant, when comparing the magnitude (OR) of associations of heterozygotes and homozygotes for $A L D H 2 * 487 L y s$, although no significance was detected for homozygotes due to a low number of samples (Table 2). Only $18.1 \%$ of TB patients had the protective allele (ALDH2 $487 \mathrm{Lys}$ ), compared with $29.7 \%$ of controls (dominant mode; OR $=0.52$ [95\% confidential interval (CI), 0.39-0.69], $\mathrm{P}=000004$ ) (Table 2).

The AF was calculated by frequency of risk genotype $($ ALDH $2 \% G l u / G l u, 70.2 \%)$ and its odds ratio (1.93) based on controls (Table 2). The AF indicates that $39.5 \%$ of TB patients can attribute their disease to the detrimental effects of $A L D H 2 * G l u / G l u$ in the Korean population.

\section{Discussion}

Tuberculosis is one of the oldest diseases known to mankind; it is also a leading cause of death among adults, and it kills almost 500 children each day worldwide. More than $90 \%$ of TB-related deaths occur in developing countries. The incidence of $\mathrm{TB}$ was declared a global emergency by the World Health Organization (WHO) in 1993, with around 8-10 million new cases of the disease each year and 2-3 million deaths worldwide (WHO Report, 2005). A worldwide health problem that reached a peak in the nineteenth century, it was thought to have been brought under control by the 1960s due to active public health measures and the use of modern drug therapies. However, this complacency led to reduced funding for the diagnosis and treatment of TB at the same time that the bacterium was developing resistance to the drugs used to treat it. The problem has been compounded since the 1980s by the emergence of a new population of vulnerable individuals-those infected with HIV.

Approximately one third of the world's population is latently infected with Mycobacterium tuberculosis, which causes TB. However, only $10 \%$ of those infected are estimated to progress to active (clinical) TB. A large body of epidemiological data links polymorphisms in various host genes to increased susceptibility to TB [15-17]. These host genetic factors are among the important determinants of susceptibility to the disease [18]. The doubly high risk of disease in identical twins compared with non-identical twins [19] strongly indicates a host genetic component. There have been many studies on TB susceptibility based on candidate-gene approaches. Recently, several genomewide association studies (GWASs) identified susceptibility loci for tuberculosis on chromosome 18q11.2 [20], chromosome 11p13 [21], chromosome 20q12 [22], and eight genes involved in immune signaling [23]. 
Table 1 Analysis of genetic effect of ADH1B His47Arg and ALDH2 Glu487Lys on the risk of various diseases in a Korean population $(n=6,423)$

\begin{tabular}{|c|c|c|c|c|c|c|c|c|c|c|}
\hline \multirow[t]{2}{*}{ Loci } & \multirow[t]{2}{*}{ Disease } & \multirow[t]{2}{*}{ Group } & \multicolumn{3}{|c|}{ Genotype } & \multirow[t]{2}{*}{ Total N } & \multirow[t]{2}{*}{$\mathrm{MAF}^{\mathrm{a}}$} & \multirow[t]{2}{*}{ HWE $^{\mathbf{b}}$} & \multirow[t]{2}{*}{ OR $(95 \% \mathrm{Cl})^{c}$} & \multirow[t]{2}{*}{$P^{c}$} \\
\hline & & & $\mathrm{His} / \mathrm{His}$ & His/Arg & Arg/Arg & & & & & \\
\hline \multirow[t]{10}{*}{ ADH1B His47Arg } & Hepatitis & $C C^{d}$ & $317(59.0 \%)$ & $196(36.5 \%)$ & $24(4.5 \%)$ & 537 & 0.227 & 0.361 & $0.95(0.76-1.18)$ & 0.64 \\
\hline & & $S R^{d}$ & $243(57.1 \%)$ & $165(38.7 \%)$ & $18(4.2 \%)$ & 426 & 0.236 & 0.125 & & \\
\hline & Asthma & Case & $708(56.2 \%)$ & 464(36.9\%) & $87(6.9 \%)$ & 1259 & 0.253 & 0.358 & $0.99(0.84-1.17)$ & 0.91 \\
\hline & & Control & $295(54.8 \%)$ & $210(39.2 \%)$ & $32(6.0 \%)$ & 537 & 0.256 & 0.503 & & \\
\hline & T2DM & Case & $449(60.3 \%)$ & 251(33.7\%) & $45(6.0 \%)$ & 745 & 0.229 & 0.214 & $0.91(0.76-1.08)$ & 0.28 \\
\hline & & Control & $349(56.8 \%)$ & $227(37.0 \%)$ & $38(6.2 \%)$ & 614 & 0.247 & 0.893 & & \\
\hline & Alcoholism $^{\mathrm{e}}$ & Case & $217(39.5 \%)$ & $145(26.4 \%)$ & 187(34.1\%) & 549 & 0.473 & $3.172 \times 10^{-28}$ & $2.38(2.00-2.82)$ & $1.28 \mathrm{E}-22$ \\
\hline & & Control & 298(61.7\%) & 155(32.1\%) & $30(6.2 \%)$ & 483 & 0.223 & 0.893 & & \\
\hline & $\mathrm{TB}$ & Case & $273(57.2 \%)$ & 169(35.4\%) & $35(7.4 \%)$ & 477 & 0.251 & 0.217 & $1.01(0.84-1.22)$ & 0.89 \\
\hline & & Control & $450(56.5 \%)$ & 297(37.3\%) & $49(6.2 \%)$ & 796 & 0.248 & 0.999 & & \\
\hline \multirow[t]{10}{*}{ ALDH2Glu487Lys } & Hepatitis & $\mathrm{CC}$ & $372(69.3 \%)$ & $157(29.2 \%)$ & $8(1.5 \%)$ & 537 & 0.161 & 0.058 & $1.02(0.80-1.31)$ & 0.88 \\
\hline & & SR & $305(71.6 \%)$ & 107(25.1\%) & 14(3.3\%) & 426 & 0.158 & 0.230 & & \\
\hline & Asthma & Case & $860(68.3 \%)$ & $358(28.4 \%)$ & $41(3.3 \%)$ & 1259 & 0.175 & 0.617 & $1.17(0.96-1.41)$ & 0.12 \\
\hline & & Control & $385(71.7 \%)$ & 139(25.9\%) & $13(2.4 \%)$ & 537 & 0.154 & 0.914 & & \\
\hline & $\mathrm{T} 2 \mathrm{DM}$ & Case & 498(66.8\%) & $224(30.1 \%)$ & $23(3.1 \%)$ & 745 & 0.181 & 0.718 & $1.05(0.87-1.28)$ & 0.60 \\
\hline & & Control & $426(69.4 \%)$ & 163(26.5\%) & $25(4.1 \%)$ & 614 & 0.173 & 0.066 & & \\
\hline & Alcoholisme & Case & $530(96.5 \%)$ & $19(3.5 \%)$ & $0(0.0 \%)$ & 549 & 0.017 & 0.680 & $0.10(0.06-0.16)$ & $3.88 \mathrm{E}-20$ \\
\hline & & Control & $346(73.6 \%)$ & $122(25.3 \%)$ & $15(3.1 \%)$ & 483 & 0.265 & 0.297 & & \\
\hline & $\mathrm{TB}$ & Case & $391(82 \%)$ & $78(16.4 \%)$ & $8(1.7 \%)$ & 477 & 0.099 & 0.082 & $0.57(0.45-0.74)$ & 0.00001 \\
\hline & & Control & $559(70.2 \%)$ & $216(27.1 \%)$ & $21(2.6 \%)$ & 796 & 0.162 & 0.980 & & \\
\hline
\end{tabular}

${ }^{a}$ MAF: minor allele frequency.

${ }^{\mathrm{b}} P$-value of genotype distribution deviation from Hardy-Weinberg equilibrium.

'Logistic regression models (co-dominant model) were used for calculating odds ratios ( $95 \%$ confidential interval) and corresponding $P$-values.

${ }^{d}$ CC: chronic carrier/SR: spontaneously recovered.

${ }^{\mathrm{K}} \mathrm{Kim}$ et al. (2008) [9].

Bold faces indicate $P<0.05$.

In this study, we demonstrated that one functional polymorphism in a primary alcohol-metabolizing enzyme (ALDH2Glu487Lys) is a genetic component underlying susceptibility to TB in a Korean population. The protective effect of $A L D H 2 * 487$ Lys on TB could be explained through the well-known function of this variant in alcohol metabolism. Although $A D H 1 B * 47$ is involved in alcohol elimination from the blood after consumption (alcohol to acetaldehyde), it is not directly involved in alcohol-related adverse reactions. However, the $A L D H 2 * 487 L y s$ allele encodes an inactive converting enzyme (acetaldehyde into acetate), resulting in excessive accumulated acetaldehyde, which causes alcohol-related adverse reactions including flushing, palpitation, nausea, headache, drowsiness, breathlessness, and general discomfort $[1,5,6]$. These adverse reactions likely lead to reduced alcohol abuse, which in turn helps to maintain better general health and reduces the risk of $\mathrm{TB}$, along with other confounding factors.

Interestingly, the genotype distribution of $A L D H 2$ differs greatly between Asian, especially East Asian, and other major populations. In fact, $A L D H 2 * 487 L y s$ has only been detected in East Asian populations [24]. The hypothesis of selection pressure for lower ALDH2

Table 2 Analysis of genetic effect of ALDH2 Glu487Lys on risk of TB $(n=1,273)$

\begin{tabular}{|c|c|c|c|c|c|c|c|c|c|c|}
\hline \multirow[t]{2}{*}{ Genotype } & \multirow[t]{2}{*}{ TB } & \multirow[t]{2}{*}{ Control } & \multicolumn{2}{|c|}{ Referent analysis $^{a}$} & \multicolumn{2}{|c|}{ Co-dominant model } & \multicolumn{2}{|c|}{ Dominant model } & \multicolumn{2}{|c|}{ Recessive model } \\
\hline & & & OR $(95 \% \mathrm{Cl})$ & $\mathbf{P}$ & OR $(95 \% \mathrm{Cl})$ & $P$ & OR $(95 \% \mathrm{Cl})$ & $P$ & OR $(95 \% \mathrm{Cl})$ & $P$ \\
\hline Glu/Glu & $391(82 \%)$ & $559(70.2 \%)$ & 1 & - & & & & & & \\
\hline Glu/Lys & $78(16.4 \%)$ & $216(27.1 \%)$ & $0.52(0.39-0.69)$ & 0.000008 & $0.57(0.45-0.74)$ & 0.00001 & $0.52(0.39-0.69)$ & 0.000004 & $0.63(0.28-1.43)$ & 0.27 \\
\hline Lys/Lys & $8(1.7 \%)$ & $21(2.6 \%)$ & $0.55(0.24-1.24)$ & 0.15 & & & & & & \\
\hline
\end{tabular}

${ }^{a}$ Odds ratio and $P$-value of individual genotype as compared to common genotype in referent analysis. Bold faces indicate $P<0.05$. 
(mediated by $A L D H 2 * 487 L y s$ ), against some endemic disease(s) in areas with high frequency of $A L D H 2 * 487 L y s$, seems like one of the most plausible explanations. It is not easy to prove, historically, given the time period during which it operated. However, based on the higher prevalence of TB and higher frequencies of $A L D H 2 * 487 L y s$ in East Asian populations, a likely hypothesis is that TB is or was an endemic disease in Korean and possibly Japanese and Chinese populations. This could have exerted selection pressure that accounts for the higher frequencies of $A L D H 2 * 487 L y s$ in Asian populations.

\section{Conclusions}

In this paper, we demonstrated that the well-known functional polymorphism of a primary alcohol-metabolizing enzyme (ALDH2 Glu487Lys) has a genetic association with the risk of TB. We also offer evidence that TB may have been an endemic disease in Asian populations, which exerted selection pressure resulting in higher frequencies of $A L D H 2 * 487 L y s$. In addition, the AF indicates that alcoholism in $39.5 \%$ of TB patients in the Korean population can be attributed to the detrimental effect of $A L D H 2 * 487$ Glu, which suggests that this polymorphism is one of the genetic components of TB, at least among Koreans.

\author{
Abbreviations \\ ADH: Alcohol dehydrogenase; ALDH: Aldehyde dehydrogenase; \\ TB: Tuberculosis; AF: Attributable fraction.
}

\section{Competing interests}

The authors declare that they have no competing interest to report.

\section{Authors' contributions}

SK Park and HS Cheong carried out the molecular genetic studies, participated in the sequence alignment, and drafted the manuscript. SK Park, HS Lee, and KS Park recruited samples in this study. BL Park participated in the genotyping. SK Park and HD Shin developed the design of the study and performed the statistical analysis. HD Shin conceived of the study, participated in its coordination, and helped to draft the manuscript. All authors read and approved the final manuscript.

\section{Acknowledgments}

This work was supported by Basic Science Research Program through the National Research Foundation of Korea (NRF) funded by the Ministry of Education (No. 2011-0021659) and Engineering Foundation (KOSEF) funded by the Korean government (MEST) (No. 2009-0080157).

\footnotetext{
Author details

${ }^{1}$ Sorokdo National Hospital, 65 Doyang-eup, Goheung-gun, Jeonnam 548-904, Republic of Korea. ${ }^{2}$ Genome Research Center for Allergy and Respiratory Diseases, Soonchunhyang University Bucheon Hospital and Seoul Hospital, Seoul, Republic of Korea. ${ }^{3}$ Department of Internal Medicine and Liver Research Institute, Seoul National University, 28 Yungun-dong, Chongro-Gu, Seoul 110-744, Republic of Korea. ${ }^{4}$ Department of Internal Medicine, Seoul National University College of Medicine, Seoul 110-744, Republic of Korea. ${ }^{5}$ Department of Genetic Epidemiology, SNP Genetics, Inc., 1 Shinsu-dong, Mapo-gu, Seoul 121-742, Republic of Korea. ${ }^{6}$ Department of Life Science, Sogang University, 1 Shinsu-dong, Mapo-gu, Seoul 121-742, Republic of Korea.
}

Received: 18 July 2012 Accepted: 27 March 2014

Published: 2 April 2014

\section{References}

1. Bosron WF, Li TK: Genetic polymorphism of human liver alcohol and aldehyde dehydrogenases, and their relationship to alcohol metabolism and alcoholism. Hepatology 1986, 6:502-510.

2. Yokoyama A, Muramatsu T, Omori T, Yokoyama T, Matsushita S, Higuchi S, Maruyama K, Ishii H: Alcohol and aldehyde dehydrogenase gene polymorphisms and oropharyngolaryngeal, esophageal and stomach cancers in Japanese alcoholics. Carcinogenesis 2001, 22:433-439.

3. Marchand LL, Wilkinson GR, Wilkens LR: Genetic and dietary predictors of CYP2E1 activity: a phenotyping study in Hawaii Japanese using chlorzoxazone. Cancer Epidemiol Biomarkers Prev 1999, 8:495-500.

4. Crabb DW, Edenberg HJ, Bosron WF, Li TK: Genotypes for aldehyde dehydrogenase deficiency and alcohol sensitivity. The inactive ALDH2(2) allele is dominant. J Clin Invest 1989, 83:314-316.

5. Yoshida A, Hsu LC, Yasunami M: Genetics of human alcohol-metabolizing enzymes. Prog Nucleic Acid Res Mol Biol 1991, 40:255-287.

6. Matsuo K, Wakai K, Hirose K, Ito H, Saito T, Tajima K: Alcohol dehydrogenase 2 His47Arg polymorphism influences drinking habit independently of aldehyde dehydrogenase 2 Glu487Lys polymorphism: analysis of 2,299 Japanese subjects. Cancer Epidemiol Biomarkers Prev 2006, 15:1009-1013.

7. Choi IG, Kee BS, Son HG, Ham BJ, Yang BH, Kim SH, Lee JS, Son BK, Lee BY, Lee SY, Chai YG, Shin HD: Genetic polymorphisms of alcohol and aldehyde dehydrogenase, dopamine and serotonin transporters in familial and non-familial alcoholism. Eur Neuropsychopharmacol 2006, 16:123-128.

8. Choi IG, Son HG, Yang BH, Kim SH, Lee JS, Chai YG, Son BK, Kee BS, Park BL, Kim LH, Choi YH, Shin HD: Scanning of genetic effects of alcohol metabolism gene (ADH1B and ADH1C) polymorphisms on the risk of alcoholism. Hum Mutat 2005, 26:224-234.

9. Kim DJ, Choi IG, Park BL, Lee BC, Ham BJ, Yoon S, Bae JS, Cheong HS, Shin HD: Major genetic components underlying alcoholism in Korean population. Hum Mol Genet 2008, 17:854-858.

10. Park BL, Kim YJ, Cheong HS, Lee SO, Han CS, Yoon JH, Park JH, Chang HS, Park CS, Lee HS, Shin HD: HDAC10 promoter polymorphism associated with development of HCC among chronic HBV patients. Biochem Biophys Res Commun 2007, 363:776-781.

11. Park JH, Chang HS, Park CS, Jang AS, Park BL, Rhim TY, Uh ST, Kim YH, Chung IY, Shin HD: Association analysis of CD40 polymorphisms with asthma and the level of serum total lgE. Am J Respir Crit Care Med 2007, 175:775-782.

12. Shin HD, Park BL, Kim LH, Jung HS, Cho YM, Moon MK, Park YJ, Lee HK, Park KS: Genetic polymorphisms in peroxisome proliferator-activated receptor delta associated with obesity. Diabetes 2004, 53:847-851.

13. Shin HD, Cheong HS, Park BL, Kim LH, Han CS, Lee IH, Park SK: Common MCL1 polymorphisms associated with risk of tuberculosis. BMB Rep 2008, 41:334-337.

14. Adams MJ Jr, Khoury MJ, James LM: The use of attributable fraction in the design and interpretation of epidemiologic studies. J Clin Epidemiol 1989, 42:659-662.

15. Bellamy R: Genetic susceptibility to tuberculosis. Clin Chest Med 2005, 26:233-246. vi.

16. Fernando SL, Britton WJ: Genetic susceptibility to mycobacterial disease in humans. Immunol Cell Biol 2006, 84:125-137.

17. Hill AV: Aspects of genetic susceptibility to human infectious diseases. Annu Rev Genet 2006, 40:469-486.

18. Casanova JL, Abel L: Genetic dissection of immunity to mycobacteria: the human model. Annu Rev Immunol 2002, 20:581-620.

19. Comstock GW: Tuberculosis in twins: a re-analysis of the Prophit survey. Am Rev Respir Dis 1978, 117:621-624.

20. Thye T, Vannberg FO, Wong SH, Owusu-Dabo E, Osei I, Gyapong J, Sirugo G, Sisay-Joof F, Enimil A, Chinbuah MA, Floyd S, Warndorff DK, Sichali L, Malema S, Crampin AC, Ngwira B, Teo YY, Small K, Rockett K, Kwiatkowski D, Fine PE, Hill PC, Newport M, Lienhardt C, Adegbola RA, Corrah T, Ziegler A, Morris AP, Meyer CG, Horstmann RD, et al: Genome-wide association analyses identifies a susceptibility locus for tuberculosis on chromosome 18q11.2. Nat Genet 2010, 42:739-741.

21. Chimusa ER, Zaitlen N, Daya M, Moller M, van Helden PD, Mulder NJ, Price AL, Hoal EG: Genome-wide association study of ancestry-specific TB risk in the South African Coloured population. Hum Mol Genet 2014, 23(3):796-809. 
22. Mahasirimongkol $\mathrm{S}$, Yanai $\mathrm{H}$, Mushiroda T, Promphittayarat $\mathrm{W}$,

Wattanapokayakit S, Phromjai J, Yuliwulandari R, Wichukchinda N, Yowang A, Yamada N, Kantipong P, Takahashi A, Kubo M, Sawanpanyalert P, Kamatani N, Nakamura Y, Tokunaga K: Genome-wide association studies of tuberculosis in Asians identify distinct at-risk locus for young tuberculosis. J Hum Genet 2012, 57:363-367.

23. Png E, Alisjahbana B, Sahiratmadja E, Marzuki S, Nelwan R, Balabanova Y, Nikolayevskyy V, Drobniewski F, Nejentsev S, Adnan I, van de Vosse E, Hibberd ML, van Crevel R, Ottenhoff TH, Seielstad M: A genome wide association study of pulmonary tuberculosis susceptibility in Indonesians. BMC Med Genet 2012, 13:5

24. Oota H, Pakstis AJ, Bonne-Tamir B, Goldman D, Grigorenko E, Kajuna SL, Karoma NJ, Kungulilo S, Lu RB, Odunsi K, Okonofua F, Zhukova OV, Kidd JR, Kidd KK: The evolution and population genetics of the ALDH2 locus: random genetic drift, selection, and low levels of recombination Ann Hum Genet 2004, 68:93-109.

doi:10.1186/1471-2350-15-40

Cite this article as: Park et al.: Functional polymorphism in aldehyde dehydrogenase-2 gene associated with risk of tuberculosis. BMC Medical Genetics 2014 15:40.

\section{Submit your next manuscript to BioMed Central and take full advantage of:}

- Convenient online submission

- Thorough peer review

- No space constraints or color figure charges

- Immediate publication on acceptance

- Inclusion in PubMed, CAS, Scopus and Google Scholar

- Research which is freely available for redistribution 